\title{
A case of delivery of a pregnant woman with COVID-19 infection in Daegu, Korea
}

\author{
Jin-Gon Bae, MD¹, Jin-Kyeong Ha, MD¹, Myoung Kwon, MD¹, Hak-Youle Park, MD², Won-Joon Seong, MD³, \\ Seong-Yeon Hong, MD ${ }^{4}$ \\ Department of Obstetrics and Gynecology, ${ }^{1}$ Keimyung University School of Medicine, ${ }^{2}$ Fatima Hospital, ${ }^{3}$ Graduate School of Medicine, Kyungpook \\ National University, ${ }^{4}$ Catholic University of Daegu School of Medicine, Daegu, Korea
}

Coronavirus disease 2019 (COVID-19) is caused by severe acute respiratory syndrome coronavirus 2 (SARS-CoV-2), which is affiliated with the $\beta$-coronavirus subgroup, which includes SARS-CoV and Middle East respiratory syndrome coronavirus (MERS-CoV), but is far more infectious than the 2. Because it is potentially life-threatening to infants and pregnant women with weak immune systems, clinical manifestations and vertical transmission of COVID-19 are matters of interest. Staff of the obstetrics department of university hospitals in Daegu and of the Daegu metropolitan government designated Daegu Fatima Hospital for the delivery of pregnant women with suspected and confirmed SARS-CoV-2 infection. Thirteen pregnant women with laboratory-confirmed COVID-19 were identified. Among them was a 28-year-old pregnant woman who had recovered from COVID-19 and had given birth to a healthy girl at 38 weeks of gestational age. We present our uncommon experience with a brief review of literatures.

Keywords: COVID-19; Pregnancy; Obstetric delivery; Coronavirus

\section{Introduction}

The first case of coronavirus disease 2019 (COVID-19) was announced in China on January 20, 2020, and the World Health Organization declared the global outbreak of COVID-19 as a pandemic on March 11. A month later, after the first case in Korea, an outbreak of COVID-19 occurred in Daegu, Korea. To prevent the spread of COVID-19 to pregnant women, we developed a control system in Daegu, and it seemed to be effective. There was no case of fetal demise or abortion. We report the delivery of a healthy girl at 38 weeks of gestation by a woman who had recovered from COVID-19.

\section{Case report}

On February 12, 2020, a 28-year-old woman, gravida 1 para 0 , who had no previous illness notified the public health center that she had a fever and cough for 2 days. She had been in contact with her husband, who had a confirmed case of COVID-19 pneumonia, and she was also 36 weeks pregnant. She tested positive for COVID-19, confirming that she was infected. Because the number of confirmed cases suddenly skyrocketed, a sufficient governmental control strategy was not yet established at that time. No hospital had been designated for the care of pregnant women with COVID-19, and "self-isolation" was recommended. Fortunately, her clinical manifestation was mild, and she complied well with the advice and daily monitoring of the public health center for 2 weeks. During this period, she was not given treatment. On February 23, staff of the obstetrics department of university hospitals in Daegu and of the Daegu metropolitan govern-

Received: 2020.04.16. Revised: 2020.07.26. Accepted: 2020.08.12. Corresponding author: Jin-Gon Bae, MD

Department of Obstetrics and Gynecology, Keimyung University Dongsan Medical Center, Keimyung University School of Medicine, 1035 Dalgubeol-daero, Dalseo-gu, Daegu 42601, Korea E-mail: jgonmd@gmail.com

https://orcid.org/0000-0001-6127-162X

Articles published in Obstet Gynecol Sci are open-access, distributed under the terms of the Creative Commons Attribution Non-Commercial License (http://creativecommons. org/licenses/by-nc/3.0/) which permits unrestricted non-commercial use, distribution, and reproduction in any medium, provided the original work is properly cited.

Copyright $\odot 2020$ Korean Society of Obstetrics and Gynecology 


\section{Obstetrics \& Gynecology Science}

Vol. 63, No. 6, 2020

ment designated Daegu Fatima Hospital for the delivery of pregnant women with suspected and confirmed severe acute respiratory syndrome coronavirus 2 (SARS-CoV-2) infection.

On the 13th day after the confirmation of the infection, the patient was admitted to the designated hospital for delivery at 38 weeks of pregnancy because she was concerned about the condition of the baby. Upon admission, physical examination findings were normal. Laboratory tests revealed a leukocyte count of $5,380 / \mathrm{mm}^{3}$, a C-reactive protein level of $0.15 \mathrm{mg} / \mathrm{L}$, and other results within normal limits. Chest radiographs revealed no active pathologic finding (Fig. 1). A fetal ultrasound scan showed adequate growth for gestational age without any abnormality, and the nonstress test results were normal. The mother was retested for COVID-19, but the results were not available at the time of delivery.

After consultation with an anesthesiologist, a neonatologist, a pulmonologist, and a nosocomial infection controller, she gave birth to a girl weighing 3,130 g via cesarean delivery on maternal request under spinal anesthesia in a negative-pressure operating room staffed by personnel with adequate personal protective equipment. To avoid the risk

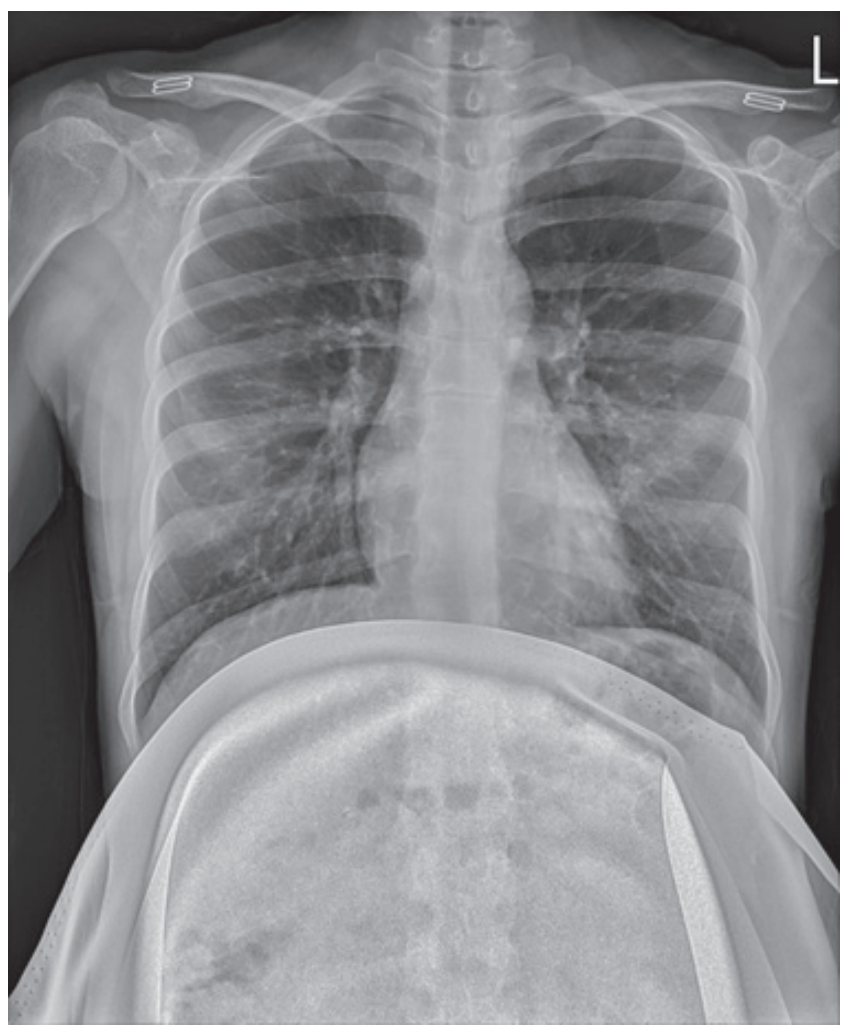

Fig. 1. Plain chest radiograph in the mother showed no definitive pathologic findings. of infection through direct contact, the umbilical cord was clamped right away. The newborn's Apgar scores were 9 and 10 at 1 and 5 minutes, respectively. After delivery, the mother and infant were transferred to separate isolation rooms that were fumigated later. The neonate was kept isolated without any skin-to-skin contact and tested for COVID-19 infection by quantitative reverse-transcription polymerase chain reaction. A nasopharyngeal swab, amniotic fluid, placental tissue, and umbilical venous blood yielded negative results twice in 24-hour interval. A pathological examination of the placenta also yielded no abnormal findings. Breast milk was substituted with formula milk to minimize the risk of infection to the neonate via respiratory droplet or direct contact. Chest computed tomography in the mother after delivery showed the finding of atypical pneumonia, but her clinical symptoms were improved, and the test result for COVID-19 was negative (Fig. 2). On the 5th day after delivery, the mother and infant were discharged without any other symptoms associated with COVID-19.

\section{Discussion}

Coronaviruses are enveloped, spherical, nonsegmented, and

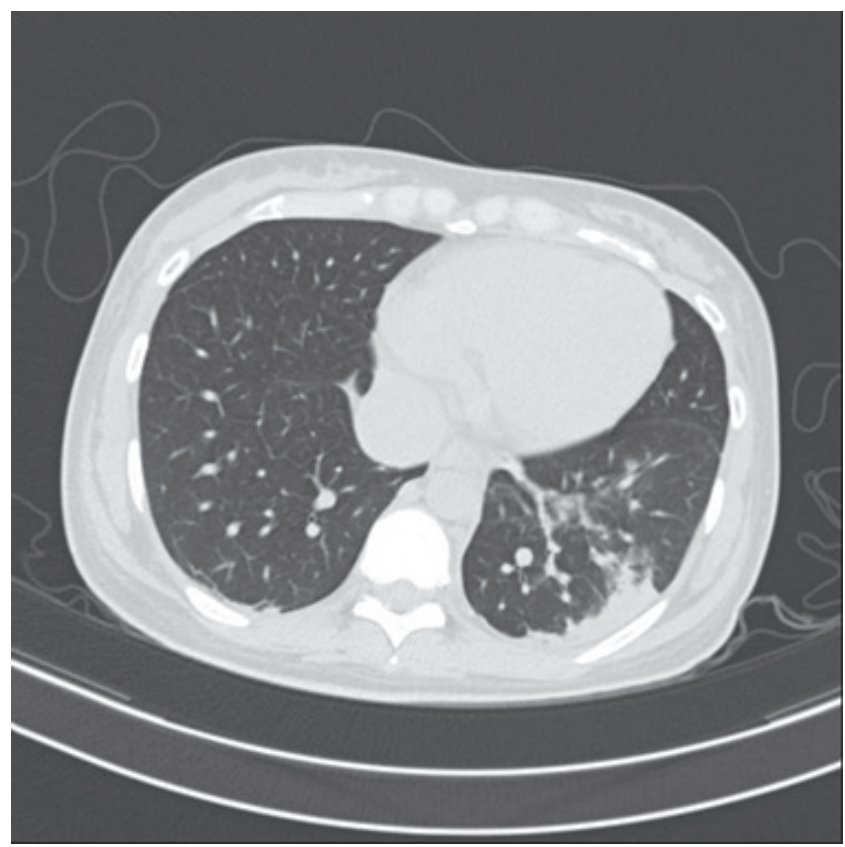

Fig. 2. Chest computed tomography in the mother revealed subpleural consolidation and peribronchial infiltration in the left lower lung field. 


\section{Obstetrics \& Gynecology Science}

Jin-Gon Bae, et al. Delivery of woman with COVID-19 in Daegu

positive-strand RNA viruses. SARS-CoV-2 and MERS-CoV are the $\beta$-coronaviruses among 4 genera of coronaviruses [1]. SARS-CoV-2 causes COVID-19 [2]. Unfortunately, there is no definite evidence that pregnant women are at a greater risk for COVID-19 or pneumonia compared to other people. However, pregnant women are vulnerable to respiratory diseases due to immunologic and physiologic changes during pregnancy, and SARS-COV and MERS-COV are notorious for causing severe respiratory complications during pregnancy [3].

Common clinical signs of COVID-19 are fever, cough, myalgia, headache, abdominal pain, and diarrhea. Severe pneumonia, acute respiratory distress syndrome, and death can occur $[4,5]$. One general medical concern is the lack of extensive information about the delivery of mothers with COVID-19 in Korea, but viral pneumonia during pregnancy is known to be related to preterm delivery, fetal growth restriction, and perinatal mortality [6].

Generally, SARS-CoV-2, like influenza, is known to be spread through small respiratory droplets from the nose or mouth when an infected person coughs and exhales. Spread might also occur through the fecal-oral route, as clinical signs of COVID-19 are similar to those of SARS [7]. The prevalence and results of congenital infections with SARSCoV-2 are not clear. Chen et al. reported 9 pregnant women with confirmed COVID-19 during the third trimester. All 9 were delivered via cesarean section, and Apgar scores ranged from 8 to 9 at 1 minute and from 9 to 10 at 5 minutes [8]. In another series of 9 pregnant women, Zhu et al. [9] reported 6 cases of fetal distress and 6 cases of preterm delivery, but none of the infants had serious neonatal complications. In the aforementioned 18 cases, no neonate had laboratory-confirmed COVID-19 infection or pneumonia; however, all neonates born to mothers with COVID-19 should be isolated because knowledge regarding COVID-19 is still limited, and SARS-CoV, which is related to $\beta$-coronaviruses, produces various clinical and histological abnormalities in the placenta [10].

Because guidelines for antimicrobial treatment during pregnancy have not yet been published, antiviral medication for COVID-19 infection and antibiotics for secondary bacterial infections should be carefully discussed by specialists in microbiology, virology, obstetrics, and neonatology if infective symptoms are to be managed. In severe confirmed cases, conservative blood pressure management, fluid balance, and oxygen saturation should be considered, and fetal heart rate should be monitored carefully because sudden changes in fetal heart rate might indicate the aggravation of maternal respiratory symptoms $[11,12]$.

Regarding preterm labor treatment, corticosteroids for fetal lung maturation should be administered cautiously because they may slow down recovery from the viral infection. Therefore, it is not recommended to use tocolytics to delay delivery until the fetal lungs mature with corticosteroid treatment. It is also not clear which tocolytics would be safer in pregnant women with COVID-19 [13].

COVID-19 itself is not a reason for early delivery; instead, various maternal conditions should influence decisions about delivery. COVID-19 is also not a contraindication to vaginal delivery. If labor is spontaneous and progresses properly, vaginal delivery could be performed, but efforts to reduce respiratory droplets, reduce the risk of exposure, and shorten the second stage of labor are needed. Regardless of delivery method, both vaginal delivery and cesarean section should be performed in a dedicated negative-pressure operating room by personnel with adequate personal protective equipment (respirator or effective mask, goggles or face shield, surgical gown, and gloves) [14]. To minimize exposure, a route to the delivery room for infected pregnant women should be prepared in advance, and after transfer, the route should be restricted and fumigated as soon as possible.

Although the possibility of vertical transmission of SARSCoV-2 during pregnancy is not clear, direct infection through contact after delivery is possible. Hence, prompt clamping of the umbilical cord might be safer than delayed clamping [15]. It is rational to presume that a neonate born to a mother with COVID-19 could be infected, and such neonates should be isolated from other neonates. Moreover, the evidence of the safety of breastfeeding by women with COVID-19 is still not clear.

As mentioned, pregnant women are very vulnerable to infection and pneumonia. It is important and reasonable to manage pregnant woman with COVID-19, but it is of greater importance that other uninfected women should not be exposed to the infection. If all perinatal centers had participated in treating women with confirmed COVID-19, they could have become contaminated, and high-risk pregnancies could not possibly be managed.

To effectively manage pregnant women with confirmed COVID-19 and preserve the capacity of the management 


\section{Obstetrics \& Gynecology Science}

Vol. 63, No. 6, 2020

for uninfected pregnant women at a high risk for complications, a task force for pregnancy in Daegu city appointed one general hospital (Daegu Fatima Hospital) for the delivery of pregnant women with confirmed or suspected COVID-19 and another general hospital (Daegu Dongsan Hospital) for isolation and conservative management. All the obstetrical staff of the university hospital in Daegu confined their duties to the designated hospitals.

On April 6, 2020, the cumulative total number of COVID-19 cases in Daegu was 6,768, and 13 of the patients were pregnant women. Of these 13 women, 8 were confirmed to have COVID-19 in the first trimester, 3 in the second trimester, and 2 in the third trimester. Our patient-who was diagnosed with COVID-19 in the third trimester-gave birth to a healthy girl at full term. Fortunately, clinical manifestations of all 13 cases were mild, and there was no case of abortion or fetal demise.

\section{Conflict of interest}

No potential conflict of interest relevant to this article was reported.

\section{Ethical approval}

The study was completely explained to the patient and performed in accordance with the principles of the Declaration of Helsinki. Written informed consent is attached.

\section{Patient consent}

The patient provided written informed consent for the publication and the use of her images.

\section{References}

1. Cui J, Li F, Shi ZL. Origin and evolution of pathogenic coronaviruses. Nat Rev Microbiol 2019;17:181-92.

2. Lu R, Zhao X, Li J, Niu P, Yang B, Wu H, et al. Genomic characterisation and epidemiology of 2019 novel coronavirus: implications for virus origins and receptor bind- ing. Lancet 2020;395:565-74.

3. Schwartz DA, Graham AL. Potential maternal and infant outcomes from (Wuhan) coronavirus 2019$\mathrm{nCoV}$ infecting pregnant women: lessons from SARS, MERS, and other human coronavirus infections. Viruses 2020;12:194.

4. Huang C, Wang Y, Li X, Ren L, Zhao J, Hu Y, et al. Clinical features of patients infected with 2019 novel coronavirus in Wuhan, China. Lancet 2020;395:497-506.

5. Wang D, Hu B, Hu C, Zhu F, Liu X, Zhang J, et al. Clinical characteristics of 138 hospitalized patients with 2019 novel coronavirus-infected pneumonia in Wuhan, China. JAMA 2020;323:1061-9.

6. Madinger NE, Greenspoon JS, Ellrodt AG. Pneumonia during pregnancy: Has modern technology improved maternal and fetal outcome? Am J Obstet Gynecol 1989;161:657-62.

7. Holshue ML, DeBolt C, Lindquist S, Lofy KH, Wiesman $J$, Bruce $\mathrm{H}$, et al. First case of 2019 novel coronavirus in the United States. N Engl J Med 2020;382:929-36.

8. Chen H, Guo J, Wang C, Luo F, Yu X, Zhang W, et al. Clinical characteristics and intrauterine vertical transmission potential of COVID-19 infection in nine pregnant women: a retrospective review of medical records. Lancet 2020;395:809-15.

9. Zhu H, Wang L, Fang C, Peng S, Zhang L, Chang G, et al. Clinical analysis of 10 neonates born to mothers with 2019-nCoV pneumonia. Transl Pediatr 2020;9:51-60.

10. Ng WF, Wong SF, Lam A, Mak YF, Yao H, Lee KC, et al. The placentas of patients with severe acute respiratory syndrome: a pathophysiological evaluation. Pathology 2006;38:210-8.

11. Rasmussen SA, Smulian JC, Lednicky JA, Wen TS, Jamieson DJ. Coronavirus Disease 2019 (COVID-19) and pregnancy: what obstetricians need to know. Am J Obstet Gynecol 2020;222:415-26.

12. Chen D, Yang H, Cao Y, Cheng W, Duan T, Fan C, et al. Expert consensus for managing pregnant women and neonates born to mothers with suspected or confirmed novel coronavirus (COVID-19) infection. Int J Gynaecol Obstet 2020;149:130-6.

13. Arabi YM, Mandourah Y, Al-Hameed F, Sindi AA, Almekhlafi GA, Hussein MA, et al. Corticosteroid therapy for critically ill patients with Middle East respiratory syndrome. Am J Respir Crit Care Med 2018;197:757-67. 


\section{Obstetrics \& Gynecology Science}

Jin-Gon Bae, et al. Delivery of woman with COVID-19 in Daegu

14. Poon LC, Yang H, Lee JC, Copel JA, Leung TY, Zhang Y, et al. ISUOG Interim Guidance on 2019 novel coronavirus infection during pregnancy and puerperium: information for healthcare professionals. Ultrasound Obstet
Gynecol 2020;55:700-8.

15. Mullins E, Evans D, Viner RM, O'Brien P, Morris E. Coronavirus in pregnancy and delivery: rapid review. Ultrasound Obstet Gynecol 2020;55:586-92. 